\title{
Laparoscopic gastrectomy in obese gastric cancer patients: a comparative study with non-obese patients and evaluation of difference in laparoscopic methods
}

Ke Chen ${ }^{1}$, Yu Pan ${ }^{1}$, Shu-ting Zhai ${ }^{1}$, Jia-qin Cai ${ }^{1}$, Qi-long Chen ${ }^{1}$, Ding-wei Chen ${ }^{1}$, Yi-ping Zhu ${ }^{1}$, Yu Zhang ${ }^{2}$, Ya-ping Zhang ${ }^{3}$, Hendi Maher ${ }^{4}$ and Xian-fa Wang ${ }^{1 *}$

\begin{abstract}
Background: Obesity is a growing epidemic around the world, and obese patients are generally regarded as high risk for surgery compared with normal weight patients. The purpose of this study was to evaluate the influence of obesity on the surgical outcomes of laparoscopic gastrectomy $(\mathrm{LG})$ for gastric cancer.

Methods: We reviewed data for all patients undergoing LG for gastric cancer at our institute between October 2004 and December 2016. Patients were divided into non-obese and obese groups and the perioperative outcomes were compared. Furthermore, a subgroup analysis was conducted to evaluate which of the two commonly used methods of LG, laparoscopic-assisted gastrectomy (LAG) and totally laparoscopic gastrectomy (TLG), is more suitable for obese patients.

Results: A total of 1691 patients, 1255 non-obese and 436 obese or overweight patients, underwent LG during the study period. The mean operation time was significantly longer in the obese group than in the non-obese group (209.9 \pm 29.7 vs. $227.2 \pm 25.7 \mathrm{~min}, P<0.01)$, and intraoperative blood loss was significantly lower in the non-obese group $(113.4 \pm 34.1$ vs. $136.9 \pm 36.7 \mathrm{ml}, P<0.01)$. Time to first flatus, time to oral intake, and postoperative hospital stay were significantly shorter in the non-obese group than in the obese group ( $3.3 \pm 0.8$ vs. $3.6 \pm 0.9$ days; $4.3 \pm 1.0$ vs. $4.6 \pm 1.0$ days; and 9 . $0 \pm 2.2$ vs. $9.6 \pm 2.2$ days, respectively; $P<0.01) .119(9.5 \%)$ of the non-obese patients had postoperative complications as compared to $44(10.1 \%)$ of the obese patients $(P=0.71)$. In the subgroup analysis of all patients, TLG showed improved results for early surgical outcomes compared to LAG, mainly due to its advantages in obese patients.

Conclusions: Obesity is associated with long operation time, increased blood loss, and slow recovery after laparoscopic gastric resection but does not affect intraoperative security or effectiveness. TLG may have less negative results in obese patients than LAG due to a variety of reasons. Our analysis shows that TLG is more advantageous, with regard to early surgical outcomes, for obese patients.
\end{abstract}

Keywords: Laparoscopic gastrectomy, Stomach neoplasms, Obesity, Body mass index, Morbidity

\footnotetext{
*Correspondence: srrshwxf@163.com

'Department of General Surgery, Sir Run Run Shaw Hospital, School of

Medicine, Zhejiang University, 3 East Qingchun Road, Hangzhou, Zhejiang

Province 310016, China

Full list of author information is available at the end of the article
} 


\section{Background}

Gastric cancer, as the third major course of the world's cancer-related death, is still the fifth most commonly seen cancer, despite the decreased mortality [1]. Radical gastrectomy with regional lymph node dissection is the only potentially available curative therapy though the survival of the patients is improved by adjuvant chemotherapy [2-5]. Since laparoscopic gastrectomy (LG) was first reported in 1994 for the treatment of early stage gastric adenocarcinoma [6], this technique has been rapidly adopted within East Asia. The advantages of LG include decreased pain, better cosmesis, faster recovery, fewer complications, and quicker return to normal movement compared to open surgery [7-15]. Furthermore, evidence continues to show no difference between patients undergoing open or laparoscopic surgery for oncologic outcomes [16-18]. The two commonly used approaches of LG for gastric cancer are totally laparoscopic gastrectomy (TLG) and laparoscopic-assisted gastrectomy (LAG). Perigastric lymphadenectomy in both techniques can be conducted under the laparoscopy. Nevertheless, an intracorporeal anastomosis characterizes the former one without the need of an auxiliary incision while the latter one needs an epigastrium auxiliary incision for safe en bloc extraction of the specimen to complete reconstruction of the digestive tract.

As one of the most essential health issues in the world, obesity has been widely known to aggravate numerous medical issues [19], for instance, hypertension, diabetes mellitus, lipid disorder, and obstructive sleep apnea, all of which can affect the surgical outcomes negatively [20]. In fact, the rate of obesity continues to increase worldwide in spite of the negative effects on human health. Therefore, laparoscopic gastric surgeons tend to see a growing number of overweight or obese patients, which has, and will continue to, increase complications. [21-26]. Thus, the advantages which have been mentioned previously have enhanced the application of the LG to high-risk patients, like obese people, who suffer from increased morbidity after open gastrectomy in comparison with normal weight patients. [23-26]. With respect to the laparoscopic method, some have found increased complication rates or slower recovery $[27,28]$, whereas some have reported equivalent benefits and postoperative outcomes following LG in obese patients in comparison with non-obese ones [29-33]. Thus, it remains uncertain whether the use of a laparoscopic method can reduce the difference in the morbidity or recovery between non-obese and obese patients who are suffering from gastric cancer and receiving gastrectomy. Besides, it is reported that TLG could contribute to the improvement of early surgical outcomes in overweight or obese patients compared to LAG [34]. However, such results are still not confirmed by large sample studies.
Therefore, this study aimed to evaluate the effect of obesity on outcomes in laparoscopic gastric surgery based on results from our high volume center. Concurrently, subgroup analysis was carried out to determine which was more suitable of the two LG methods for obese gastric cancer patients.

\section{Methods \\ Patients}

A retrospective review of patients receiving LG from a prospectively maintained database of gastric adenocarcinoma disease between October 2004 and December 2016 at Sir Run Run Shaw Hospital was performed. All surgeons in our institution have been performing laparoscopic surgery for over 2 years, and the seniors had more than 5 years of experience. Written consent was acquired from everyone before enrollment in the study. This research was approved by the Zhejiang University's Ethics Committee.

\section{Surgical procedure}

With the patient in the supine position, mobilization of the stomach and en bloc systematic lymph node dissection was performed via five trocars under a pneumoperitoneum. Total or distal gastrectomy was performed, according to tumor location, size, and depth of invasion. Proximal gastrectomy was not used in our center because of the relatively higher rate of reflux esophagitis. $\mathrm{D}_{2}$ lymphadenectomy was undertaken complying with the rules of the Gastric Cancer Treatment Guidelines 2011 by the Japanese Gastric Cancer Association [35]. Total gastrectomy was performed with spleen preservation. Anastomosis was completed extracorporeally or intracorporeally. Initially, an epigastrium auxiliary incision was made to facilitate the excision of the specimen and the reconstruction of the digestive tract. However, subsequent advancement in laparoscopic instruments and increased experience in the performance of intricate laparoscopic gastrointestinal procedures made us start using intracorporeal anastomosis by stapler or handsewn techniques. The surgical procedures are described in detail in our previously published articles [36-39].

\section{Patient data evaluation}

According to preoperative body mass index (BMI), patients were assigned to the obese group (BMI $>25 \mathrm{~kg} / \mathrm{m}^{2}$ ) and the non-obese (BMI $25<=\mathrm{kg} / \mathrm{m}^{2}$ ). Despite the World Health Organization's definition of obesity being a BMI over $30 \mathrm{~kg} / \mathrm{m}^{2}$, we used $25 \mathrm{~kg} / \mathrm{m}^{2}$ as our cutoff because the average BMI for Asian people is lower than the BMI for non-Asian people, especially when compared to Western populations. Statistics about the demographics of patients, postoperative outcomes and the surgical procedure were gathered. Clinical and pathological staging were determined according to the tumor-node-metastasis (TNM) model and 
the American Joint Committee on Cancer (the 7th edition). Comparisons were conducted between the two groups, regarding estimated blood loss (EBL), length of hospital stay, duration of operation, time to oral intake, time to flatus, amount of retrieved lymph nodes, mortality and morbidity.

\section{Subgroup analysis}

To evaluate the benefits of the two different LG approaches, relevant differences between LAG and TLG cases were compared among obese and non-obese patients. Furthermore, LAG and TLG cases were divided into laparoscopic-assisted distal gastrectomy (LADG), laparoscopic-assisted total gastrectomy (LATG) and totally laparoscopic distal gastrectomy (TLDG), totally laparoscopic total gastrectomy (TLTG), respectively, which were also compared between obese versus nonobese patients to confirm whether or not the possible benefits are related to surgical extension.

\section{Statistical analysis}

Results were presented as mean \pm standard deviations (SDs). Continuous variables were compared using the Student's $t$ test and categorical variables were compared with $\chi^{2}$ test or the Fisher exact probability test. Differences with $P$ values $(P<0.05)$ were considered statistically significant. All statistical analyses were performed with SPSS software, version 18.0 (SPSS Inc., Chicago, United States).

\section{Results}

\section{Patient characteristics and pathological features}

Table 1 shows the clinical characteristics and pathologic features of the patients. A total of 1691 patients, 1255 non-obese and 436 obese patients, underwent LG during the study period. The proportion of males was higher in the obese cohort than in the non-obese cohort $(61.9 \%$ vs. $72.4 \%, P<0.01)$. Otherwise, the two cohorts were similar with respect to preoperative risk factors such as age, the American Society of Anesthesiologists' score (ASA), tumor size and TNM stage. However, more

Table 1 Comparison of the clinicopathological characteristics

\begin{tabular}{llll}
\hline Variable & $\begin{array}{l}\text { Non-obese } \\
(n=1255)\end{array}$ & $\begin{array}{l}\text { Obese } \\
(n=436)\end{array}$ & $P$ value \\
\hline Age (years) & $58.2 \pm 11.1$ & $58.0 \pm 11.0$ & 0.78 \\
Gender (M/F) & $777 / 478$ & $320 / 116$ & $<0.01$ \\
ASA classification (I/II/III) & $593 / 610 / 52$ & $226 / 182 / 28$ & 0.02 \\
Tumor size (cm) & $3.7 \pm 1.7$ & $3.7 \pm 1.7$ & 0.91 \\
TNM stage (I/II/III) & $655 / 275 / 325$ & $211 / 103 / 122$ & 0.39 \\
Surgical extension (D/T) & $869 / 386$ & $336 / 100$ & $<0.01$ \\
\hline
\end{tabular}

$M$ male, $F$ female, $D$ distal gastrectomy, $T$ total gatrectomy patients in the non-obese cohort underwent total gastrectomy $(30.8 \%$ vs. $22.9 \%, P<0.01)$.

\section{Intraoperative and postoperative outcomes}

The intraoperative findings and subsequent postoperative recovery are displayed in Table 2 . The mean operation time in the obese cohort was $17.3 \mathrm{~min}$ longer than for non-obese $(209.9 \pm 29.7$ vs. $227.2 \pm 25.7 \mathrm{~min}, P<0.01)$. Intraoperative blood loss was lower in the non-obese cohort than the obese one $(113.4 \pm 34.1$ vs. $136.9 \pm 36.7 \mathrm{ml}, P<0.01)$. The difference in the number of harvested lymph nodes between groups was not significant $(35.3 \pm 9.8$ vs. $34.7 \pm 8.7, P=0.27)$. The mean time to first flatus was shorter in the non-obese cohort than in the obese cohort $(3.3 \pm 0.8$ vs. $3.6 \pm 0.9$ days, $P<0.01)$, similarly the early time to restart diet postoperatively $(4.3 \pm 1.0$ vs. $4.6 \pm 1.0$ days, $P<0.01)$. A shorter length of hospital stay was also observed in the nonobese cohort $(9.0 \pm 2.2$ vs. $9.6 \pm 2.2$ days, $P<0.01)$.

There was no postoperative mortality in both nonobese cohort and obese cohort. The complications after surgery are listed in Table 3 . The morbidity rate in the non-obese cohort was $9.5 \%$ (119/1255 patients) and $10.1 \%$ (44/436 patients) in the obese cohort, overall difference was not significant $(P=0.71)$. The leading complications in the non-obese cohort were abdominal abscess (17 cases, $1.4 \%)$ and stasis (18 cases, $1.4 \%)$. Other complications were anastomotic leakage $(n=5)$, anastomotic stricture $(n=5)$, anastomotic bleeding $(n=8)$, intracorporeal hemorrhage $(n=11)$, pancreatic leakage $(n=14)$, ileus $(n=4)$, lymphorrhea $(n=14)$, and wound infection $(n=2)$. The most common complications in the obese cohort were also abdominal abscess (7 cases, 1.6\%) and stasis (11 cases, 2.5\%). In addition, ileus (6 cases, $1.4 \%)$ and wound infection (5 cases, $1.1 \%$ ) were relatively common in obese patients. Other complications included anastomotic leakage $(n=1)$, anastomotic bleeding $(n=1)$, intracorporeal hemorrhage $(n=2)$, and lymphorrhea $(n=3)$.

Table 2 Comparison of surgical outcomes and postoperative recovery

\begin{tabular}{llll}
\hline Variable & $\begin{array}{l}\text { Non-obese } \\
(n=1255)\end{array}$ & $\begin{array}{l}\text { Obese } \\
(n=436)\end{array}$ & $P$ value \\
\hline Operation time (min) & $209.9 \pm 29.7$ & $227.2 \pm 25.7$ & $<0.01$ \\
Blood loss (mL) & $113.4 \pm 34.1$ & $136.9 \pm 36.7$ & $<0.01$ \\
Number of retrieved lymph nodes & $35.3 \pm 9.8$ & $34.7 \pm 8.7$ & 0.27 \\
Time to first flatus (days) & $3.3 \pm 0.8$ & $3.6 \pm 0.9$ & $<0.01$ \\
Time to starting liquid diet (days) & $4.3 \pm 1.0$ & $4.6 \pm 1.0$ & $<0.01$ \\
Postoperative hospital stay (days) & $9.0 \pm 2.2$ & $9.6 \pm 2.2$ & $<0.01$ \\
\hline
\end{tabular}


Table 3 Comparison of postoperative complications

\begin{tabular}{llll}
\hline Variable & $\begin{array}{l}\text { Non-obese } \\
(n=1255)\end{array}$ & $\begin{array}{l}\text { Obese } \\
(n=436)\end{array}$ & $P$ value \\
\hline Overall complications (\%) & $119(9.5)$ & $44(10.1)$ & 0.71 \\
Anastomotic leakage (\%) & $5(0.4)$ & $1(0.2)$ & \\
Anastomotic stricture (\%) & $6(0.5)$ & $0(0.0)$ & \\
Anastomotic bleeding (\%) & $8(0.6)$ & $1(0.2)$ & \\
Intracorporeal hemorrhage (\%) & $11(0.9)$ & $2(0.5)$ & \\
Abdominal abscess (\%) & $17(1.4)$ & $7(1.6)$ & \\
Stasis (\%) & $18(1.4)$ & $11(2.5)$ & \\
Pancreatic leakage (\%) & $14(1.1)$ & $0(0.0)$ & \\
Ileus (\%) & $4(0.3)$ & $6(1.4)$ & \\
Lymphorrhea (\%) & $14(1.1)$ & $3(0.7)$ \\
Wound infection (\%) & $2(0.2)$ & $5(1.1)$ & \\
Others (\%) & $20(1.6)$ & $8(1.8)$ & \\
\hline
\end{tabular}

\section{Subgroup analysis}

Table 4 lists the clinical characteristics and pathologic features of the overall, non-obese, and obese patients whom underwent LAG and TLG. More patients in the LAG cohort underwent total gastrectomy. Besides, the TLG group had a more advanced tumor stage $(P=0.03)$. Otherwise, the two cohorts were similar with respect to age, gender, ASA score, and tumor size.

Surgical outcomes and postoperative recovery are shown in Table 5. Overall the mean operation time and blood loss were superior in the TLG group than those in the LAG group with significant differences (operation time: $220.2 \pm 33.5$ vs. $210.0 \pm 25.6 \mathrm{~min}, P<0.01$, blood loss: $122.5 \pm 39.8$ vs. $117.1 \pm 33.30 \mathrm{~mL}, P<0.01)$. The numbers of retrieved lymph nodes were not significantly different between the two groups (34.7 \pm 9.7 vs. $35.4 \pm 9.4, P=0.11)$. The time to first flatus and duration of stay were significantly lower in the TLG group (first flatus: $3.4 \pm 0.9$ vs. $3.3 \pm 0.8$ days, $P=0.02$, hospital stay: $9.3 \pm 2.6$ vs. $9.0 \pm 1.9 \mathrm{~mL}, P=0.03)$. The time to starting food intake was also lower in the TLG group with a marginal difference (4.4 \pm 0.9 vs. $4.3 \pm 1.1$ days, $P=0.08$ ).
In the analysis of the obese subgroup, the operation time, blood loss, time to first flatus and diet, and duration of stay were also superior in the TLG group than in the LAG group $(P<0.05)$. However, in the non-obese subgroup analysis, only the operation time was significantly shorter in the TLG group, other parameters were not significantly different.

Table 6 presents postoperative complications in two groups. For all patients, the postoperative complication rate was somewhat lower in the TLG group, but the differences were not significant $(10.6 \%$ vs. $8.9 \%, P=0.23)$ and for non-obese patients, the postoperative complications were also not significantly different. However, in obese patients, the overall rate of complications was higher in the LAG cohort than in the TLG cohort with a significant difference $(12.6 \%$ vs. $8.6 \%, P<0.01)$. Especially, higher rates for ileus, stasis, and wound infection were observed in the LAG group.

Tables 7 and 8 present the surgical outcomes and postoperative recovery for distal or total gastrectomy, respectively. Similar to Table 6, in obese group, regardless of LAG subgroup or TLG subgroup, the surgical and perioperative outcomes were favorable in TLG. But in the non-obese group, these advantages were not obvious.

\section{Discussion}

Despite a decrease in incidence, gastric adenocarcinoma is still the third most deadly cancer worldwide and surgical resection and proper perigastric lymphadenectomy is the only treatment option for increasing the survival rate $[1,40]$. Laparoscopic surgery has been proposed as a promising method for the therapy of gastric cancer $[41,42]$. Another fact is that people around the world are getting fatter. Furthermore, obesity is no longer just found in wealthy nations. It is now a worldwide problem and the rate has almost doubled since the 1980s [19]. Therefore, there is an increasing need to improve minimally invasive approaches for obese gastric cancer patients.

Our results suggest that LG in obese or overweight gastric cancer patients poses an increased technical challenge as demonstrated by longer operating time,

Table 4 Comparison of the clinicopathological characteristics in subgroup analysis

\begin{tabular}{|c|c|c|c|c|c|c|c|c|c|}
\hline \multirow[t]{2}{*}{ Variable } & \multicolumn{3}{|l|}{ Overall } & \multicolumn{3}{|l|}{ Non-obese } & \multicolumn{3}{|l|}{ Obese } \\
\hline & $\operatorname{LAG}(n=724)$ & TLG $(n=967)$ & $P$ value & $\operatorname{LAG}(n=557)$ & TLG $(n=698)$ & $P$ value & $\mathrm{LAG}(n=167)$ & TLG $(n=269)$ & $P$ value \\
\hline Age (years) & $58.7 \pm 11.0$ & $57.7 \pm 11.0$ & 0.08 & $58.6 \pm 10.9$ & $57.9 \pm 11.2$ & 0.26 & $59.1 \pm 11.3$ & $57.4 \pm 10.7$ & 0.12 \\
\hline Gender (M/F) & $478 / 246$ & $619 / 348$ & 0.39 & $351 / 206$ & $426 / 272$ & 0.47 & $127 / 40$ & $193 / 76$ & 0.32 \\
\hline $\mathrm{ASA}(|/||/|||)$ & $339 / 353 / 32$ & $480 / 439 / 48$ & 0.39 & $259 / 276 / 22$ & $334 / 334 / 30$ & 0.82 & $80 / 77 / 10$ & $146 / 105 / 18$ & 0.36 \\
\hline Tumor size (cm) & $3.7 \pm 1.7$ & $3.6 \pm 1.7$ & 0.22 & $3.7 \pm 1.7$ & $3.6 \pm 1.6$ & 0.36 & $3.8 \pm 1.6$ & $3.6 \pm 1.7$ & 0.40 \\
\hline TNM stage (I/I/IIII) & 398/149/177 & $468 / 229 / 270$ & 0.03 & 309/113/135 & $346 / 162 / 190$ & 0.12 & $89 / 36 / 42$ & $122 / 67 / 80$ & 0.28 \\
\hline Surgical extension $(\mathrm{D} / \mathrm{T})$ & $416 / 308$ & 789/178 & $<0.01$ & $308 / 249$ & $561 / 137$ & $<0.01$ & $108 / 59$ & $228 / 41$ & $<0.01$ \\
\hline
\end{tabular}

$M$ male, $F$ female, $D$ distal gastrectomy, $T$ total gatrectomy 
Table 5 Comparison of surgical outcomes and postoperative recovery in subgroup analysis

\begin{tabular}{|c|c|c|c|c|c|c|c|c|c|}
\hline \multirow[t]{2}{*}{ Variable } & \multicolumn{3}{|l|}{ Overall } & \multicolumn{3}{|l|}{ Non-obese } & \multicolumn{3}{|l|}{ Obese } \\
\hline & $\begin{array}{l}\text { LAG } \\
(n=724)\end{array}$ & $\begin{array}{l}\text { TLG } \\
(n=967)\end{array}$ & $P$ value & $\begin{array}{l}\text { LAG } \\
(n=557)\end{array}$ & $\begin{array}{l}\text { TLG } \\
(n=698)\end{array}$ & $P$ value & $\begin{array}{l}\text { LAG } \\
(n=167)\end{array}$ & $\begin{array}{l}\text { TLG } \\
(n=269)\end{array}$ & $P$ value \\
\hline Operation time (min) & $220.2 \pm 33.5$ & $210.0 \pm 25.6$ & $<0.01$ & $215.4 \pm 32.9$ & $205.4 \pm 26.1$ & $<0.01$ & $236.0 \pm 30.9$ & $221.7 \pm 20.0$ & $<0.01$ \\
\hline Blood loss (mL) & $122.5 \pm 39.8$ & $117.1 \pm 33.3$ & $<0.01$ & $115.0 \pm 35.5$ & $112.1 \pm 33.0$ & 0.14 & $147.5 \pm 43.3$ & $130.3 \pm 30.2$ & $<0.01$ \\
\hline Number of RLN & $34.7 \pm 9.7$ & $35.4 \pm 9.4$ & 0.11 & $34.6 \pm 9.8$ & $35.8 \pm 9.8$ & 0.04 & $34.9 \pm 9.4$ & $34.5 \pm 8.3$ & 0.64 \\
\hline Time to first flatus (d) & $3.4 \pm 0.9$ & $3.3 \pm 0.8$ & 0.02 & $3.3 \pm 0.8$ & $3.2 \pm 0.8$ & 0.17 & $3.8 \pm 0.9$ & $3.5 \pm 0.9$ & $<0.01$ \\
\hline Time to starting diet (d) & $4.4 \pm 0.9$ & $4.3 \pm 1.1$ & 0.08 & $4.3 \pm 0.9$ & $4.3 \pm 1.1$ & 0.63 & $4.8 \pm 1.0$ & $4.5 \pm 1.1$ & $<0.01$ \\
\hline Postoperative hospital stay (d) & $9.3 \pm 2.6$ & $9.0 \pm 1.9$ & 0.03 & $9.1 \pm 2.5$ & $8.9 \pm 2.0$ & 0.12 & $9.9 \pm 2.8$ & $9.4 \pm 1.8$ & 0.03 \\
\hline
\end{tabular}

LAG laparoscopic-assisted gastrectomy, TLG totally laparoscopic gastrectomy, RLN Regional lymph nodes

increased blood loss, and later recovery compared to non-obese patients. Clearly, because of the hindered exposure to the pancreas and stomach, surgery in obese patients is more demanding technically. Under particular circumstances, the thickened omentum, mesentery and ligamentum may result in challenges in ligation, mobilization, or dissection of the lymph nodes and vessels. The fatty omentum and stomach itself can cause serious difficulties when the stomach is pulled by the assistant, excessive fat and incrassate mesenteries can also lead to problematic hemorrhage, which is difficult to stop in the narrow area caused by the adipose tissue. Presumably, due to visceral fat in obese patients, the enhanced technical difficulties and the exposure of an adequate operative field play a role in the distribution of anaesthetic agents which may lead to delayed sensation recovery from anaesthesia. All of the above inevitably increase surgical duration and blood loss. Also, the longer incision needed due to increased abdominal wall thickness in obese patients results in more postoperative pain, which inevitably lead to higher frequency of painkiller usage [43]. Subsequent gastrointestinal recovery, delayed postoperative activities, prolonged time of abdominal cavity exposure, and increased usage of analgesic drugs were the major reasons for extended postoperative hospital stay duration.

The rate of morbidity generally grew amongst obese patients; however, such difference was insignificant $(9.5 \%$ vs. $10.1 \%$ ). The relatively higher rate of overall complications in the obese cohort was due mainly to a greater incidence of wound infection, ileus and stasis. In these patients, the higher probability of wound infection may be associated with local factors, like the deeper abdominal wall and the need for longer auxiliary incisions. Nonetheless, systemic factors, for instance, poor glycaemic control and greater insulin resistance, may be involved, which can lead to greater susceptibility to bacteria. The increased ileus and stasis might be partly due to the technically difficult manipulating the fatty stomach and bowels for resection and reconstruction. After surgery, another explanation for the association of

Table 6 Comparison of postoperative complications in subgroup analysis

\begin{tabular}{|c|c|c|c|c|c|c|c|c|c|}
\hline \multirow[t]{2}{*}{ Variable } & \multicolumn{3}{|l|}{ Overall } & \multicolumn{3}{|c|}{ Non-obese } & \multicolumn{3}{|l|}{ Obese } \\
\hline & $\begin{array}{l}\text { LAG } \\
(n=724)\end{array}$ & $\begin{array}{l}\text { TLG } \\
(n=967)\end{array}$ & $P$ value & $\begin{array}{l}\mathrm{LAG} \\
(n=557)\end{array}$ & $\begin{array}{l}\text { TLG } \\
(n=698)\end{array}$ & $P$ value & $\begin{array}{l}\text { LAG } \\
(n=167)\end{array}$ & $\begin{array}{l}\text { TLG } \\
(n=269)\end{array}$ & $P$ value \\
\hline Overall complications (\%) & 77 (10.6) & $86(8.9)$ & 0.23 & $56(10.1)$ & $63(9.0)$ & 0.54 & $21(12.6)$ & $23(8.6)$ & $<0.01$ \\
\hline Anastomotic leakage (\%) & $2(0.3)$ & $4(0.4)$ & & $2(0.4)$ & $3(0.4)$ & & $0(0.0)$ & $1(0.4)$ & \\
\hline Anastomotic stricture (\%) & $3(0.4)$ & $3(0.3)$ & & $3(0.5)$ & $3(0.4)$ & & $0(0.0)$ & $0(0.0)$ & \\
\hline Anastomotic bleeding (\%) & $4(0.6)$ & $5(0.5)$ & & $4(0.7)$ & $4(0.6)$ & & $0(0.0)$ & $1(0.4)$ & \\
\hline Intracorporeal hemorrhage (\%) & $7(1.0)$ & $6(0.6)$ & & $6(1.1)$ & $5(0.7)$ & & $1(0.6)$ & $1(0.4)$ & \\
\hline Abdominal abscess (\%) & $9(1.2)$ & $15(1.6)$ & & $6(1.1)$ & $11(1.6)$ & & $3(1.8)$ & $4(1.5)$ & \\
\hline Stasis (\%) & $12(1.7)$ & $17(1.8)$ & & $7(1.3)$ & $11(1.6)$ & & $5(3.0)$ & $6(2.2)$ & \\
\hline Pancreatic leakage (\%) & $7(1.0)$ & $7(0.7)$ & & $7(1.3)$ & $7(1.0)$ & & $0(0.0)$ & $0(0.0)$ & \\
\hline lleus (\%) & $6(0.8)$ & $4(0.4)$ & & $2(0.4)$ & $2(0.3)$ & & $4(2.4)$ & $2(0.7)$ & \\
\hline Lymphorrhea (\%) & $9(1.2)$ & $8(0.8)$ & & $7(1.3)$ & $7(1.0)$ & & $2(1.2)$ & $1(0.4)$ & \\
\hline Wound infection (\%) & $5(0.7)$ & $2(0.2)$ & & $2(0.4)$ & $0(0.0)$ & & $3(1.8)$ & $2(0.7)$ & \\
\hline Others (\%) & $13(1.8)$ & $15(1.6)$ & & $10(1.8)$ & $10(1.4)$ & & $3(1.8)$ & $5(1.9)$ & \\
\hline
\end{tabular}

LAG laparoscopic-assisted gastrectomy, TLG totally laparoscopic gastrectomy 
Table 7 Comparison of surgical outcomes, postoperative recovery and postoperative complications in Subgroup analysis for distal gastrectomy

\begin{tabular}{|c|c|c|c|c|c|c|}
\hline \multirow[t]{2}{*}{ Variable } & \multicolumn{3}{|l|}{ Non-obese } & \multicolumn{3}{|l|}{ Obese } \\
\hline & $\operatorname{LADG}(n=308)$ & $\operatorname{TLDG}(n=561)$ & $P$ value & $\operatorname{LADG}(n=108)$ & $\operatorname{TLDG}(n=228)$ & $P$ value \\
\hline Operation time (min) & $198.5 \pm 21.1$ & $198.7 \pm 21.0$ & 0.89 & $227.6 \pm 25.2$ & $218.2 \pm 17.7$ & $<0.01$ \\
\hline Blood loss (mL) & $107.2 \pm 26.6$ & $110.0 \pm 32.8$ & 0.17 & $141.1 \pm 44.8$ & $129.0 \pm 30.7$ & $<0.01$ \\
\hline Number of RLN & $34.7 \pm 8.5$ & $35.5 \pm 9.7$ & 0.20 & $33.9 \pm 9.7$ & $34.1 \pm 8.7$ & 0.88 \\
\hline Time to first flatus (d) & $3.2 \pm 0.8$ & $3.2 \pm 0.8$ & 0.90 & $3.8 \pm 1.0$ & $3.5 \pm 0.9$ & 0.02 \\
\hline Time to starting diet (d) & $4.2 \pm 0.9$ & $4.2 \pm 0.9$ & 0.67 & $4.8 \pm 1.0$ & $4.5 \pm 1.0$ & 0.01 \\
\hline Postoperative hospital stay (d) & $8.7 \pm 2.0$ & $8.8 \pm 1.9$ & 0.81 & $9.8 \pm 2.6$ & $9.4 \pm 1.8$ & 0.13 \\
\hline Overall complications (\%) & $26(8.4)$ & $44(7.8)$ & 0.80 & $13(12.0)$ & $18(7.9)$ & 0.22 \\
\hline Anastomotic leakage (\%) & $1(0.3)$ & $2(0.4)$ & & $0(0.0)$ & $1(0.4)$ & \\
\hline Intracorporeal hemorrhage (\%) & $3(1.0)$ & $4(0.7)$ & & $1(0.9)$ & $1(0.4)$ & \\
\hline Anastomotic bleeding (\%) & $1(0.3)$ & $2(0.4)$ & & $0(0.0)$ & $1(0.4)$ & \\
\hline Abdominal abscess (\%) & $3(1.0)$ & $8(1.4)$ & & $2(1.9)$ & $3(1.3)$ & \\
\hline Stasis (\%) & $5(1.6)$ & $9(1.6)$ & & $3(2.8)$ & $5(2.2)$ & \\
\hline Pancreatic leakage (\%) & $4(1.3)$ & $5(0.9)$ & & $0(0.0)$ & $0(0.0)$ & \\
\hline Ileus (\%) & $0(0.0)$ & $1(0.2)$ & & $3(2.8)$ & $1(0.4)$ & \\
\hline Lymphorrhea (\%) & $3(1.0)$ & $6(1.1)$ & & $1(0.9)$ & $1(0.4)$ & \\
\hline Wound infection (\%) & $1(0.3)$ & $0(0.0)$ & & $1(0.9)$ & $1(0.4)$ & \\
\hline Others (\%) & $5(1.6)$ & $7(1.2)$ & & $2(1.9)$ & $4(1.8)$ & \\
\hline
\end{tabular}

LADG laparoscopic-assisted distal gastrectomy, TLDG totally laparoscopic distal gastrectomy, RLN Regional lymph nodes

Table 8 Comparison of surgical outcomes, postoperative recovery and postoperative complications in Subgroup analysis for total gastrectomy

\begin{tabular}{|c|c|c|c|c|c|c|}
\hline \multirow[t]{2}{*}{ Variable } & \multicolumn{3}{|l|}{ Non-obese } & \multicolumn{3}{|l|}{ Obese } \\
\hline & $\operatorname{LATG}(n=249)$ & $\operatorname{TLTG}(n=137)$ & $P$ value & $\operatorname{LATG}(n=59)$ & $\operatorname{TLTG}(n=41)$ & $P$ value \\
\hline Operation time (min) & $236.4 \pm 32.8$ & $233.1 \pm 26.8$ & 0.32 & $251.4 \pm 34.5$ & $241.5 \pm 20.7$ & 0.10 \\
\hline Blood loss (mL) & $124.7 \pm 42.1$ & $120.5 \pm 32.7$ & 0.28 & $159.2 \pm 38.2$ & $137.6 \pm 26.7$ & $<0.01$ \\
\hline Number of RLN & $34.5 \pm 11.1$ & $36.8 \pm 10.1$ & 0.04 & $36.7 \pm 8.5$ & $36.8 \pm 5.2$ & 0.96 \\
\hline Time to first flatus (d) & $3.4 \pm 0.8$ & $3.3 \pm 0.7$ & 0.21 & $3.9 \pm 0.8$ & $3.5 \pm 0.9$ & 0.04 \\
\hline Time to starting diet (d) & $4.4 \pm 0.9$ & $4.4 \pm 1.5$ & 0.96 & $4.9 \pm 0.8$ & $4.6 \pm 1.2$ & 0.15 \\
\hline Postoperative hospital stay (d) & $9.5 \pm 2.9$ & $9.3 \pm 2.1$ & 0.55 & $10.1 \pm 3.0$ & $9.3 \pm 1.6$ & 0.15 \\
\hline Overall complications (\%) & $30(12.0)$ & 19 (13.9) & 0.61 & $8(13.6)$ & $5(12.2)$ & 0.84 \\
\hline Anastomotic leakage (\%) & $1(0.4)$ & $1(0.7)$ & & $0(0.0)$ & $0(0.0)$ & \\
\hline Anastomotic stricture (\%) & $3(1.2)$ & $3(2.2)$ & & $0(0.0)$ & $0(0.0)$ & \\
\hline Anastomotic bleeding (\%) & $3(1.2)$ & $2(1.5)$ & & $0(0.0)$ & $0(0.0)$ & \\
\hline Intracorporeal hemorrhage (\%) & $3(1.2)$ & $1(0.7)$ & & $0(0.0)$ & $0(0.0)$ & \\
\hline Abdominal abscess (\%) & $3(1.2)$ & $3(2.2)$ & & $1(1.7)$ & $1(2.4)$ & \\
\hline Stasis (\%) & $2(0.8)$ & $2(1.5)$ & & $2(3.4)$ & $1(2.4)$ & \\
\hline Pancreatic leakage (\%) & $3(1.2)$ & $2(1.5)$ & & $0(0.0)$ & $0(0.0)$ & \\
\hline Ileus (\%) & $2(0.8)$ & $1(0.7)$ & & $1(1.7)$ & $1(2.4)$ & \\
\hline Lymphorrhea (\%) & $4(1.6)$ & $1(0.7)$ & & $1(1.7)$ & $0(0.0)$ & \\
\hline Wound infection (\%) & $1(0.4)$ & $0(0.0)$ & & $2(3.4)$ & $1(2.4)$ & \\
\hline Others (\%) & $5(2.0)$ & $3(2.2)$ & & $1(1.7)$ & $1(2.4)$ & \\
\hline
\end{tabular}


obesity with stasis and ileus is a delay or decrease in ambulation [44].

Our findings are concordant with the results of other large studies from Asian countries regardless of open or laparoscopic abdominal surgery [45, 46]. However, some reports had inconsistent results mainly with Western countries. According to some American studies, overweight and mildly obese patients even tended to have better outcomes than the normal weight patients $[47,48]$. Such difference could be ascribed to insufficient sample size to identify statistically significant differences. Another contributor to the discrepancy may be the inexperience of surgeons in East Asia in treating obese patients in comparison with their Western counterparts, because, in general, the average BMI for Asian people is much lower than that of Western people, despite its recent increase.

Based on our findings, LG, though less invasive compared to conventional open surgery, is still more traumatic for obese gastric cancer patients than nonobese patients. Therefore, a relatively less invasive approach for obese gastric cancer patients is urgently needed. Lee et al. reported that the advantages of robotic gastrectomy were less optimal with normal weight patients characterized by less blood loss than in over-weight patients [49]. Therefore, he argued that patients with high BMI may be good candidates for robotic surgery when deciding between minimally invasive approaches for curing gastric cancer. However, compared to operations such as rectal or prostatic surgery, which are in relatively narrow regions, gastric surgery located on the upper abdomen is relatively spacious, the superiority of the da Vinci robotic proceedure over laparoscopy is not obvious [50-52]. In addition, the downside of added costs and longer operation times compared with a laparoscopic approach is also an important consideration [53]. Because the heath care resources for Chinese patients are limited, they need to self-pay for such a costly system, it is more sensible to enhance the laparoscopic approach for obese patients rather than using the da Vinci robot.

It is well-known that there are two methods of LG with the main differences that anastomoses are performed intracorporeally or extracorporeally. TLG is regarded as incisionless, with only minimal trocar wounds and characterized by such operation of in situ, no tumor touch, more selectivity and dexterity for surgeons and total direct vision during operation [37]. These advantages may help get over the limitations of laparoscopic surgery in obese patients.

Though some observational studies and meta-analysis reported favorable outcomes of TLG compared to LAG
[54-59], there are still some studies, which included randomized controlled trials (RCTs), that failed to identify clinical advantages of TLG over LAG [60-66], however these studies did not evaluate the benefit or superiority of TLG over LAG in obese patients. Also, based on our data of non-obese patients, the outcomes of TLG are not inferior to those of LAG, but for obese patients, TLG has several advantages over LAG, such as shortened operating time, less intraoperative bleeding, earlier recovery, and fewer complications. After further analysis by dividing TLG into TLDG and TLTG, findings were similar. Our results mean that TLG could be more favorable than LAG among obese patients regardless of total or distal gastrectomy. However, given the small number of patients within this subgroup, especially in total gastrectomy of obese patents, these results should be interpreted with caution. Further studies are warranted before drawing definitive conclusions.

There are several limitations in our study. The selection bias is the most significant limitation of this research. There were great differences between obese and non-obese cohorts in patient comorbidities and surgical extensions. During earlier trials when we performed LG or at the beginning of a junior carrying out LG, surgeons often chose LAG, then started to attempt TLG only after a sufficient accumulation of laparoscopic experience. This could have affected our results. The retrospective nature at a single academic institution is another limitation. Thus, patient heterogeneity might be a potential confounder in this research. Due to the differences in operative indications and populations, direct comparisons of non-obese and obese patients seem inappropriate methodologically, when retrospective data are used. Possible sources of heterogeneity included surgeon experience, variable medical group habits and small sample sizes. Also this study only examined the short-term outcomes following LG for gastric cancer. The long-term effects of overweight and obesity on cancer mortality and quality of life remain unknown.

\section{Conclusions}

In conclusion, our study suggests that LG for gastric cancer in the obese poses an increased technical challenge as demonstrated by longer operating time, increased blood loss and later postoperative recovery compared to non-obese patients. TLG may offer several advantages compared to LAG including operation of in situ, no tumor touch, improved visualization and dexterity, which may improve outcomes, thus it is more suitable for obese patients. Future studies should focus on collecting robust prospective data that compares short-term surgical and long-term survival results in the obese for each of the existing minimally invasive operation options. 


\section{Abbreviations}

ASA: American Society of Anesthesiologists; BMl: Body mass index; EBL: Estimated blood loss; LADG: Laparoscopic-assisted distal gastrectomy; LAG: Laparoscopic-assisted gastrectomy; LATG: Laparoscopic-assisted total gastrectomy; LG: Laparoscopic gastrectomy; RCT: Randomized controlled trial; SD: Standard deviations; TLDG: Totally laparoscopic distal gastrectomy; TLG: Totally laparoscopic gastrectomy; TLTG: Totally laparoscopic total gastrectomy; TNM: Tumor-node-metastasis

\section{Acknowledgements}

Not applicable.

\section{Funding}

This work was supported by the Medical and Natural Science Foundation of Zhejiang Province, China (No.LY12H16026, No. 2013RCA028) and Chinese Medical Technology Foundation of Zhejiang Province, China (No.2012ZA087).

\section{Availability of data and materials}

The datasets during and/or analyzed during the current study are available from the corresponding author on reasonable request.

\section{Authors' contributions}

KC, YP and HM wrote the manuscript; XFW, KC, YP, STZ, QLC, DWC and YPZ1 performed the operations; YP, JQC, YZ and YPZ2 reviewed the medical records and collected data; XFW proofread and revised the manuscript; all authors read and approved the final manuscript.

\section{Competing interests}

The authors declare that they have no competing interests.

\section{Consent for publication}

Not applicable.

\section{Ethics approval and consent to participate}

Written consent was acquired from everyone before enrolment in the study. This research was approved by the Zhejiang University's Ethics Committee.

\section{Publisher's Note}

Springer Nature remains neutral with regard to jurisdictional claims in published maps and institutional affiliations.

\section{Author details}

'Department of General Surgery, Sir Run Run Shaw Hospital, School of Medicine, Zhejiang University, 3 East Qingchun Road, Hangzhou, Zhejiang Province 310016, China. ${ }^{2}$ Department of Gastroenterology, Sir Run Run Shaw Hospital, School of Medicine, Zhejiang University, 3 East Qingchun Road, Hangzhou, Zhejiang Province 310016, China. ${ }^{3}$ Department of Anesthesiology, Sir Run Run Shaw Hospital, School of Medicine, Zhejiang University, 3 East Qingchun Road, Hangzhou, Zhejiang Province 310016, China. ${ }^{4}$ School of Medicine, Zhejiang University, 866 Yuhangtang Road, Hangzhou, Zhejiang Province 310058, China.

Received: 8 February 2017 Accepted: 15 June 2017

Published online: 19 June 2017

\section{References}

1. Ferlay J, Soerjomataram I, Dikshit R, Eser S, Mathers C, Rebelo M, et al. Cancer incidence and mortality worldwide: sources, methods and major patterns in GLOBOCAN 2012. Int J Cancer. 2015;136:E359-86.

2. Sakuramoto $S$, Sasako M, Yamaguchi T, Kinoshita T, Fujii M, Nashimoto A, Furukawa H, Nakajima T, Ohashi Y, Imamura H, Higashino M, Yamamura Y, Kurita A, Arai K, ACTS-GC Group. Adjuvant chemotherapy for gastric cancer with S-1, an oral fluoropyrimidine. N Engl J Med. 2007; 357: 1810-20.

3. Bang YJ, Kim YW, Yang HK, Chung HC, Park YK, Lee KH, Lee KW, Kim YH, Noh SI, Cho JY, Mok YJ, Kim YH, Ji J, Yeh TS, Button P, Sirzén F, Noh SH, CLASSIC trial investigators. Adjuvant capecitabine and oxaliplatin for gastric cancer after D2 gastrectomy (CLASSIC): a phase 3 open-label, randomised controlled trial. Lancet. 2012;379:315-21.

4. Catalano V, Labianca R, Beretta GD, Gatta G, de Braud F, Van Cutsem E. Gastric cancer. Crit Rev Oncol Hematol. 2009;71:127-64.
5. Songun I, Putter $H$, Kranenbarg EM, Sasako M, van de Velde CJ. Surgical treatment of gastric cancer: 15-year follow-up results of the randomized nationwide Dutch $D_{1} D_{2}$ trial. Lancet Oncol. 2010;11:439-49.

6. Kitano S, Iso Y, Moriyama M, Sugimachi K. Laparoscopy-assisted Billroth I gastrectomy. Surg Laparosc Endosc. 1994;4:146-8.

7. Huscher CG, Mingoli A, Sgarzini G, Sansonetti A, Di Paola M, Recher A, et al. Laparoscopic versus open subtotal gastrectomy for distal gastric cancer: five-year results of a randomized prospective trial. Ann Surg. 2005;241:232-7.

8. Lee $\mathrm{JH}, \mathrm{Han} \mathrm{HS}$, Lee $\mathrm{JH}$. A prospective randomized study comparing open vs laparoscopy-assisted distal gastrectomy in early gastric cancer: early results. Surg Endosc. 2005;19:168-73.

9. Kim HH, Hyung WJ, Cho GS, Kim MC, Han SU, Kim W, et al. Morbidity and mortality of laparoscopic gastrectomy versus open gastrectomy for gastric cancer: an interim report-a phase III multicenter, prospective, randomized trial (KLASS trial). Ann Surg. 2010;251:417-20.

10. Kim YW, Baik YH, Yun YH, Nam BH, Kim DH, Choi IJ, et al. Improved quality of life outcomes after laparoscopy-assisted distal gastrectomy for early gastric cancer: results of a prospective randomized clinical trial. Ann Surg. 2008;248:721-7

11. Zeng YK, Yang ZL, Peng JS, Lin HS, Cai L. Laparoscopy-assisted versus open distal gastrectomy for early gastric cancer: evidence from randomized and nonrandomized clinical trials. Ann Surg. 2012;256:39-52.

12. Kim W, Kim HH, Han SU, Kim MC, Hyung WJ, Ryu SW, Cho GS, Kim CY, Yang HK, Park DJ, Song KY, Lee SI, Ryu SY, Lee JH, Lee HJ, Korean Laparo-endoscopic Gastrointestinal Surgery Study (KLASS) Group. Decreased morbidity of laparoscopic distal Gastrectomy compared with open distal Gastrectomy for stage I gastric cancer: short-term outcomes from a multicenter randomized controlled trial (KLASS-01). Ann Surg. 2016; 263: 28-35.

13. Kim DJ, Lee JH, Kim W. Comparison of the major postoperative complications between laparoscopic distal and total gastrectomies for gastric cancer using Clavien-Dindo classification. Surg Endosc. 2015;29:3196-204.

14. Hu Y, Ying M, Huang C, Wei H, Jiang Z, Peng $X$, Hu J, Du X, Wang B, Lin F, Xu J, Dong G, Mou T, Li G, Chinese Laparoscopic Gastrointestinal Surgery Study (CLASS) Group. Oncologic outcomes of laparoscopy-assisted gastrectomy for advanced gastric cancer: a large-scale multicenter retrospective cohort study from China. Surg Endosc. 2014; 28: 2048-56.

15. Oh SY, Kwon S, Lee KG, Suh YS, Choe HN, Kong SH, et al. Outcomes of minimally invasive surgery for early gastric cancer are comparable with those for open surgery: analysis of 1,013 minimally invasive surgeries at a single institution. Surg Endosc. 2014;28:789-95.

16. Lee JH, Nam BH, Ryu KW, Ryu SY, Park YK, Kim S, et al. Comparison of outcomes after laparoscopy-assisted and open total gastrectomy for early gastric cancer. Br J Surg. 2015;102:1500-5.

17. Kim HH, Han SU, Kim MC, Hyung WJ, Kim W, Lee HJ, et al. Long-term results of laparoscopic gastrectomy for gastric cancer: a large-scale case-control and case-matched Korean multicenter study. J Clin Oncol. 2014;32:627-33.

18. Chen K, Xu XW, Mou YP, Pan Y, Zhou YC, Zhang RC, et al. Systematic review and meta-analysis of laparoscopic and open gastrectomy for advanced gastric cancer. World J Surg Oncol. 2013;11:182.

19. Finucane MM, Stevens GA, Cowan MJ, Danaei G, Lin JK, Paciorek CJ, Singh GM, Gutierrez HR, Lu Y, Bahalim AN, Farzadfar F, Riley LM, Ezzati M, Global Burden of Metabolic Risk Factors of Chronic Diseases Collaborating Group (Body Mass Index). National, regional, and global trends in body-mass index since 1980: systematic analysis of health examination surveys and epidemiological studies with 960 country-years and 9.1 million participants. Lancet. 2011; 377: 557-67.

20. Lascano CA, Kaidar-Person O, Szomstein S, Rosenthal R, Wexner SD. Challenges of laparoscopic colectomy in the obese patient: a review. Am J Surg. 2006;192:357-65.

21. Silber JH, Rosenbaum PR, Kelz RR, Reinke CE, Neuman MD, Ross RN, et al. Medical and financial risks associated with surgery in the elderly obese. Ann Surg. 2012;256:79-86.

22. Yasunaga H, Horiguchi H, Matsuda S, Fushimi K, Hashimoto H, Ayanian JZ. Body mass index and outcomes following gastrointestinal cancer surgery in Japan. Br J Surg. 2013;100:1335-43.

23. Adachi W, Kobayashi M, Koike S, Rafique M, Nimura Y, Kuroda T, et al. The influence of excess body weight on the surgical treatment of patients with gastric cancer. Surg Today. 1995;25:939-45.

24. Ojima T, Iwahashi M, Nakamori M, Nakamura M, Naka T, Ishida $K$, et al. Influence of overweight on patients with gastric cancer after undergoing 
curative gastrectomy: an analysis of 689 consecutive cases managed by a single center. Arch Surg. 2009;144:351-8. discussion 358

25. Li L, Li X, Chu S, Tian J, Su J, Tian H, et al. Does overweight affect outcomes in patients undergoing gastrectomy for cancer? A meta-analysis of 25 cohort studies. Jpn J Clin Oncol. 2014:44:408-15.

26. Wu XS, Wu WG, Li ML, Yang JH, Ding QC, Zhang L, et al. Impact of being overweight on the surgical outcomes of patients with gastric cancer: a meta-analysis. World J Gastroenterol. 2013;19:4596-606.

27. Kim MG, Kim KC, Kim BS, Kim TH, Kim HS, Yook JH, et al. A totally laparoscopic distal gastrectomy can be an effective way of performing laparoscopic gastrectomy in obese patients (body mass index $\geq 30$ ). World J Surg. 2011;35:1327-32.

28. Sugimoto M, Kinoshita T, Shibasaki H, Kato Y, Gotohda N, Takahashi S, et al. Short-term outcome of total laparoscopic distal gastrectomy for overweight and obese patients with gastric cancer. Surg Endosc. 2013;27:4291-6.

29. Yasuda K, Inomata M, Shiraishi N, Izumi K, Ishikawa K, Kitano S. Laparoscopyassisted distal gastrectomy for early gastric cancer in obese and nonobese patients. Surg Endosc. 2004;18:1253-6.

30. Shim JH, Song KY, Kim SN, Park CH. Laparoscopy-assisted distal gastrectomy for overweight patients in the Asian population. Surg Today. 2009:39:481-6.

31. Lee HJ, Kim HH, Kim MC, Ryu SY, Kim W, Song KY, Cho GS, Han SU, Hyung WJ, Ryu SW, Korean Laparoscopic Gastrointestinal Surgery Study Group. The impact of a high body mass index on laparoscopy assisted gastrectomy for gastric cancer. Surg Endosc. 2009; 23: 2473-9.

32. Ohno T, Mochiki $E$, Ando H, Ogawa A, Yanai M, Toyomasu Y, et al. The benefits of laparoscopically assisted distal gastrectomy for obese patients. Surg Endosc. 2010:24:2770-5

33. Wang Z, Zhang X, Liang J, Hu J, Zeng W, Zhou Z. Short-term outcomes for laparoscopy-assisted distal gastrectomy for body mass index $\geq 30$ patients with gastric cancer. J Surg Res. 2015;195:83-8.

34. Kim MG, Kawada H, Kim BS, Kim TH, Kim KC, Yook JH, et al. A totally laparoscopic distal gastrectomy with gastroduodenostomy (TLDG) for improvement of the early surgical outcomes in high BMI patients. Surg Endosc. 2011;25:1076-82.

35. Japanese Gastric Cancer Association. Japanese gastric cancer treatment guidelines 2010 (ver. 3). Gastric Cancer. 2011;14:113-23.

36. Wang W, Chen K, Xu XW, Pan Y, Mou YP. Case-matched comparison of laparoscopy-assisted and open distal gastrectomy for gastric cancer. World J Gastroenterol. 2013;19:3672-7.

37. Chen $K$, Xu X, Mou Y, Pan Y, Zhang R, Zhou Y, et al. Totally laparoscopic distal gastrectomy with $D_{2}$ lymphadenectomy and Billroth II gastrojejunostomy for gastric cancer: short- and medium-term results of 139 consecutive cases from a single institution. Int J Med Sci. 2013;10:1462-70.

38. Chen K, Wu D, Pan Y, Cai JQ, Yan JF, Chen DW, et al. Totally laparoscopic gastrectomy using intracorporeally stapler or hand-sewn anastomosis for gastric cancer: a single-center experience of 478 consecutive cases and outcomes. World J Surg Oncol. 2016;14:115.

39. Chen K, Pan Y, Cai JQ, Xu XW, Wu D, Yan JF, et al. Intracorporeal esophagojejunostomy after totally laparoscopic total gastrectomy: a singlecenter 7-year experience. World J Gastroenterol. 2016;22:3432-40.

40. Kim JP. Current status of surgical treatment of gastric cancer. J Surg Oncol. 2002;79:79-80

41. Coburn N, Seevaratnam R, Paszat L, Helyer L, Law C, Swallow C, et al. Optimal management of gastric cancer: results from an international RAND/UCLA expert panel. Ann Surg. 2014;259:102-8.

42. Straatman J, Cuesta MA, van der Peet DL. Optimal Management of Gastric Cancer: laparoscopic versus open Gastrectomy. Ann Surg. 2015;262:e97.

43. Jung JH, Ryu SY, Jung MR, Park YK, Jeong O. Laparoscopic distal gastrectomy for gastric cancer in morbidly obese patients in South Korea. J Gastric Cancer. 2014;14:187-95.

44. Svatek RS, Fisher MB, Williams MB, Matin SF, Kamat AM, Grossman HB, et al. Age and body mass index are independent risk factors for the development of postoperative paralytic ileus after radical cystectomy. Urology. 2010;76:1419-24.

45. Khoury W, Stocchi L, Geisler D. Outcomes after laparoscopic intestinal resection in obese versus non-obese patients. Br J Surg. 2011;98:293-8.

46. Fung A, Trabulsi N, Morris M, Garfinkle R, Saleem A, Wexner SD, Vasilevsky CA, Boutros M. Laparoscopic colorectal cancer resections in the obese: a systematic review. Surg Endosc. 2016; [Epub ahead of print].

47. Mullen JT, Davenport DL, Hutter MM, Hosokawa PW, Henderson WG, Khuri SF, et al. Impact of body mass index on perioperative outcomes in patients undergoing major intra-abdominal cancer surgery. Ann Surg Oncol. 2008;15:2164-72.

48. Mullen JT, Moorman DW, Davenport DL. The obesity paradox: body mass index and outcomes in patients undergoing nonbariatric general surgery. Ann Surg. 2009;250:166-72

49. Lee J, Kim YM, Woo Y, Obama K, Noh SH, Hyung WJ. Robotic distal subtotal gastrectomy with $D_{2}$ lymphadenectomy for gastric cancer patients with high body mass index: comparison with conventional laparoscopic distal subtotal gastrectomy with $D_{2}$ lymphadenectomy. Surg Endosc. 2015;29:3251-60.

50. Hyun MH, Lee CH, Kim HJ, Tong Y, Park SS. Systematic review and metaanalysis of robotic surgery compared with conventional laparoscopic and open resections for gastric carcinoma. Br J Surg. 2013;100:1566-78.

51. Zong L, Seto Y, Aikou S, Takahashi T. Efficacy evaluation of subtotal and total gastrectomies in robotic surgery for gastric cancer compared with that in open and laparoscopic resections: a meta-analysis. PLoS One. 2014;9:e103312.

52. Shen WS, Xi HQ, Chen L, Wei B. A meta-analysis of robotic versus laparoscopic gastrectomy for gastric cancer. Surg Endosc. 2014;28:2795-802.

53. Montalti R, Patriti A, Troisi RI. Robotic versus laparoscopic hepatectomy: what is the best minimally invasive approach? Ann Surg. 2015;262:e70.

54. Song KY, Park CH, Kang HC, Kim JJ, Park SM, Jun KH, et al. Is totally laparoscopic gastrectomy less invasive than laparoscopy-assisted gastrectomy?: prospective, multicenter study. J Gastrointest Surg. 2008;12:1015-21.

55. Ikeda O, Sakaguchi Y, Aoki Y, Harimoto N, Taomoto J, Masuda T, et al. Advantages of totally laparoscopic distal gastrectomy over laparoscopically assisted distal gastrectomy for gastric cancer. Surg Endosc. 2009;23:2374-9.

56. Choi BS, Oh HK, Park SH, Park JM. Comparison of laparoscopy-assisted and totally laparoscopic distal gastrectomy: the short-term outcome at a low volume center. J Gastric Cancer. 2013;13:44-50.

57. Han G, Park JY, Kim YJ. Comparison of short-term postoperative outcomes in totally laparoscopic distal gastrectomy versus laparoscopy-assisted distal gastrectomy. J Gastric Cancer. 2014;14:105-10.

58. Gao J, Li P, Li QG, Chen J, Wang DR, Tang D. Comparison between totally laparoscopic and laparoscopically assisted distal gastrectomy for gastric cancer with a short follow-up: a meta-analysis. J Laparoendosc Adv Surg Tech A. 2013;23:693-7.

59. Zhang YX, Wu YJ, Lu GW, Xia MM. Systematic review and meta-analysis of totally laparoscopic versus laparoscopic assisted distal gastrectomy for gastric cancer. World J Surg Oncol. 2015;13:116.

60. Woo J, Lee JH, Shim KN, Jung HK, Lee HM, Lee HK. Does the difference of invasiveness between totally laparoscopic distal Gastrectomy and laparoscopyassisted distal Gastrectomy lead to a difference in early surgical outcomes? A prospective randomized trial. Ann Surg Oncol. 2015;22:1836-43.

61. Lu X, Hu Y, Liu H, Mou T, Deng Z, Wang D, et al. Short-term outcomes of intracorporeal esophagojejunostomy using the transorally inserted anvil versus extracorporeal circular anastomosis during laparoscopic total gastrectomy for gastric cancer: a propensity score matching analysis. J Surg Res. 2016;200:435-43.

62. Kim HG, Park JH, Jeong SH, Lee YJ, Ha WS, Choi SK, et al. Totally laparoscopic distal gastrectomy after learning curve completion: comparison with laparoscopy-assisted distal gastrectomy. J Gastric Cancer. 2013;13:26-33.

63. Kim DG, Choi YY, An JY, Kwon IG, Cho I, Kim YM, et al. Comparing the short-term outcomes of totally intracorporeal gastroduodenostomy with extracorporeal gastroduodenostomy after laparoscopic distal gastrectomy for gastric cancer: a single surgeon's experience and a rapid systematic review with meta-analysis. Surg Endosc. 2013;27:3153-61.

64. Kim EY, Choi HJ, Cho JB, Lee J. Totally laparoscopic Total Gastrectomy versus Laparoscopically assisted Total Gastrectomy for gastric cancer. Anticancer Res. 2016;36:1999-2003.

65. Jeong O, Jung MR, Park YK, Ryu SY. Safety and feasibility during the initial learning process of intracorporeal Billroth I (delta-shaped) anastomosis for laparoscopic distal gastrectomy. Surg Endosc. 2015;29:1522-9.

66. Chen K, Mou YP, Xu XW, Pan Y, Zhou YC, Cai JQ, et al. Comparison of shortterm surgical outcomes between totally laparoscopic and laparoscopicassisted distal gastrectomy for gastric cancer: a 10-y single-center experience with meta-analysis. J Surg Res. 2015;194:367-74. 